\title{
Farmer engagement using a precision approach to watershed-scale conservation planning: What do we know?
}

\author{
P. Ranjan, A.S. Singh, M.D. Tomer, A.M. Lewandowski, and L.S. Prokopy
}

\begin{abstract}
Farmer engagement is an integral component of conservation planning, with increased emphasis on precision placement of conservation practices. Conservation planners are increasingly turning to tools like the Agricultural Conservation Planning Framework (ACPF) - a decision support tool (DST) that provides a menu-driven approach to conservation planning. Scholarship on human dimensions of precision conservation, also known as conservation targeting, has either examined farmers' general attitudes toward targeting, or when farmers are active participants in generating targeted practice options. However, less is known about farmers' perceptions of targeting when they receive targeted conservation options for fields they farm. With the goal of filling this knowledge gap, we present findings from semistructured in-depth interviews conducted with farmers in four watersheds in the US Midwest. Results suggest that farmers are receptive toward conservation options for their farms. Several factors influenced farmers' receptiveness toward site-specific conservation targeting, such as farmers having autonomy in the targeting process, and perceiving that the process had benefits such as field-scale validation of their natural resource concerns and its potential to encourage watershed thinking. Results also highlight the potential of conservation targeting in motivating conservation behavior. Recommendations for future conservation targeting include being mindful of the scale of the map and the amount of information presented, having boots on the ground, and engaging farmers one-on-one to motivate conservation behavior.
\end{abstract}

Key words: Agricultural Conservation Planning Framework-decision support toolsdisproportionality - precision conservation — semistructured interviews — watershed planning

\begin{abstract}
Farmer engagement is an integral component of conservation planning. A precision approach to conservation planning, also known as conservation targeting, is a novel conservation planning approach that helps site conservation practices in locations with the highest potential for improvement. The underlying rationale behind precision placement of conservation practices is disproportionality, i.e., certain sections of the agricultural landscape cause a large amount of environmental degradation (Nowak et al. 2006), in part because of the presence of "critical source areas" (CSAs), which physically have the largest potential impact on surface water quality. Disproportionality,
\end{abstract}

therefore, provides a salient and pragmatic rationale for conservation planners to engage with farmers owning farmland in CSAs. Conservation planners use data from geographic information system (GIS)enabled planning technologies to provide science-based technical assistance and conservation recommendations to farmers. To that end, owing to government support for multi-agency and multistakeholder collaborative initiatives such as the Conservation Effects Assessment Project (CEAP), several GIS-enabled decision support tools (DSTs) have been evaluated and developed (Duriancik et al. 2008). DSTs are tools that facilitate evidence-based decision-making,

Received April 30, 2019; Revised January 17, 2020 ; Accepted January 27, 2020; Published online April 25, 2020. including but not limited to identification of CSAs, both at the farm scale and the small watershed scale (Rose et al. 2016; Konopacky and Ristino 2017). Identification of CSAs, however, is just the first step toward the end goal of conservation implementation, which requires farmers' buy-in into the results generated by DSTs.

Scholarship on understanding the human dimensions of conservation targeting, to the best of our knowledge, has examined farmers' general attitudes toward this concept (Arbuckle 2013). Scholars have also examined the role of engaging farmers and landowners to devise targeted recommendations for their farms (Kalcic et al. 2014, 2015; Zimmerman et al. 2019). Others have examined the role of utilizing maps showing conservation priorities under the purview of collaborative and community-based conservation and management of natural resources (Gallo and Goodchild 2012). Outside the context of agriculture, scholars have examined stakeholder engagement in general when using GIS data, commonly referred as Public Participation Geographic Information Systems (PPGIS) (Sieber 2006). Taken together, current scholarship on the human dimensions of conservation targeting highlights the following two dominant trends: (1) farmers' support for conservation targeting, and (2) bottom-up approaches to conservation planning that engage farmers/ stakeholders in generating recommendations. In contrast, owing to technological advancements and institutional support for evaluation and development of DSTs, conservation planners increasingly have the ability to identify CSAs, and subsequently target those areas. The current scholarship and practice on conservation targeting and DSTs, therefore, begs the question: does farmer support for conser-

Pranay Ranjan (corresponding author) is a postdoctoral research asssociate, Department of Forestry and Natural Resources, Purdue University, West Lafayette, Indiana. Ajay S. Singh is an assistant professor, California State University, Sacramento, Sacramento, California. Mark D. Tomer is a research soil scientist, USDA Agricultural Research Service (ARS), National Laboratory for Agriculture and the Environment, Ames, lowa. Ann M. Lewandowski is a research and extension coordinator, University of Minnesota Water Resources Center, St. Paul, Minnesota. Linda S. Prokopy is a professor, Department of Forestry and Natural Resources, Purdue University, West Lafayette, Indiana. 
vation targeting translate into their willingness to adopt practices if their farm is identified as a CSA, i.e., if farmers themselves are the recipient of watershed-based targeting?

We keep this question at the core of our inquiry and present findings from interviews conducted with farmers who received field-specific conservation practice options generated using data sets and maps from the Agricultural Conservation Planning Framework (ACPF)—a DST that facilitates identification of field-specific opportunities for placement of conservation practices (Tomer et al. 2013, 2015; Porter et al. 2018). The ACPF is designed for use at Hydrologic Unit Code 12 (HUC 12) subwatershed scale (typically 6,070 to 16,187 ha $[15,000$ to $40,000 \mathrm{ac}]$ ). The ACPF provides a nonprioritized menu of conservation practice options, although placement options can easily be ranked based on simple metrics such as area treated or wetland area, depending on the practice. The resulting data sets and maps can provide an open format to help conservation planners increase farmer engagement, especially where social and economic factors, environmental benefits of specific practices, and landscape-specific (i.e., upstream and downstream) alternatives can be included/ considered (figure 1).

The overarching questions of this study are the following: (1) What are farmers' perceptions toward conservation targeting? (2) Whether and how do farmers' conservation targeting perceptions relate to their support for conservation practice options identified on their farm? (3) Whether and how do farmers' receptiveness toward targeted practice-placements motivate them to engage in conservation behavior? We address these knowledge gaps using qualitative research methods to help advance the scholarship on human dimensions of conservation targeting by distinguishing between farmers' generalized perceptions toward conservation targeting, as opposed to receiving targeted practice options for their fields.

\section{Materials and Methods}

The data for this study come from semistructured in-depth interviews with farmers in four watersheds in the US Midwest. Qualitative research is appropriate for the types of questions posed that require a more in-depth understanding of how farmers perceive conservation planning results and act, rather than how prevalent those perceptions are within the agricultural community (Prokopy 2011). Watersheds for selection in this study were identified using the ACPF website of the North Central Region Water Network (https://acpf4watersheds.org). The website contains a map showing the watersheds where ACPF analyses have been conducted, along with the contact information of the conservation planner involved with running the toolbox. Our criteria for selecting watersheds for this study was whether ACPF results, including data sets and maps generated by the ACPF, were used by conservation planners to engage with farmers. To develop a list of watersheds that met our criteria we contacted conservation planners in a given watershed via email and phone calls and asked them if they had used ACPF results for farmer engagement. Four watersheds, three in Iowa and one in Minnesota, fit our criteria and were selected for this study (figure 2).

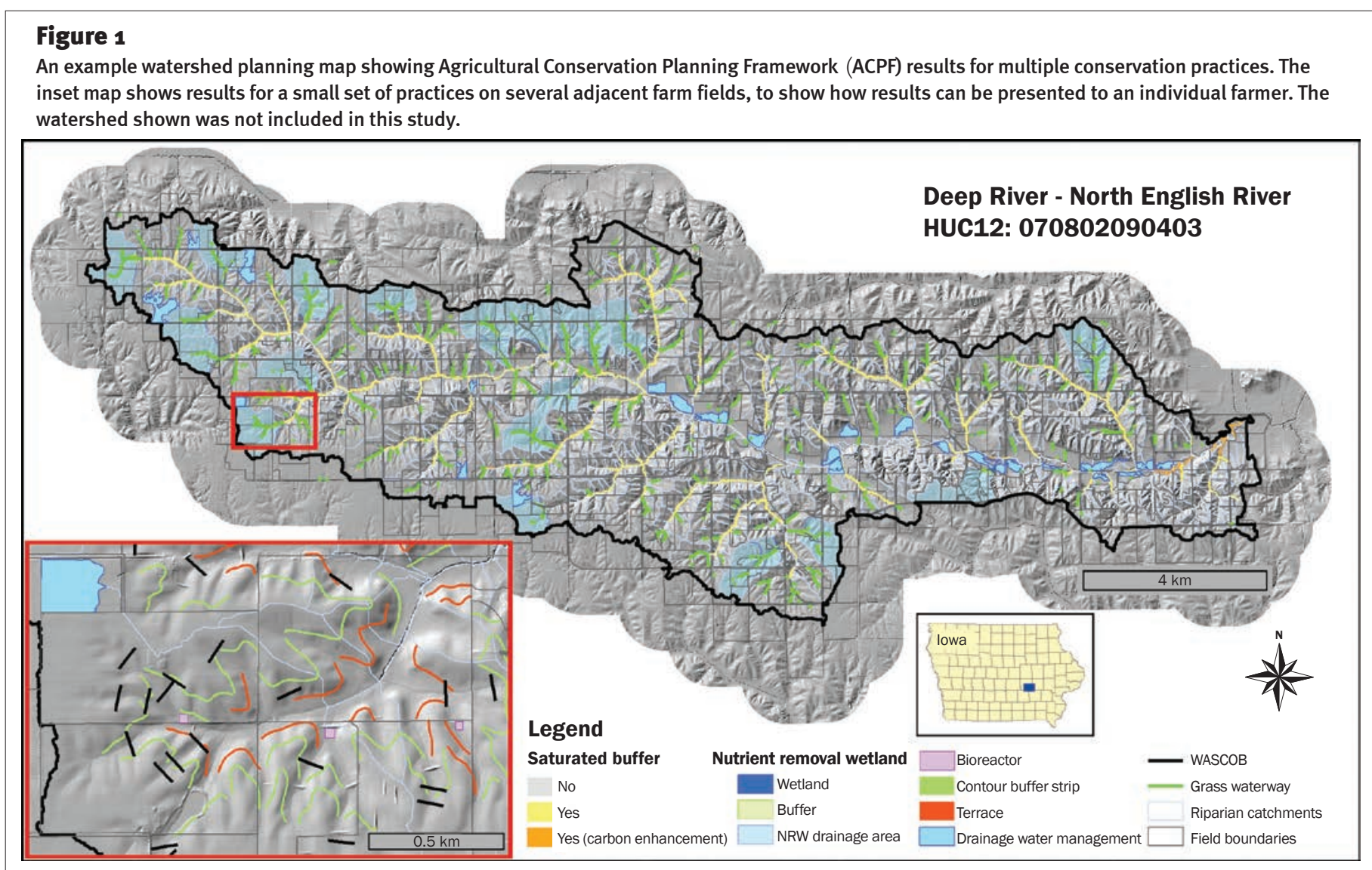




\section{Figure 2}

Study watersheds in lowa and Minnesota.

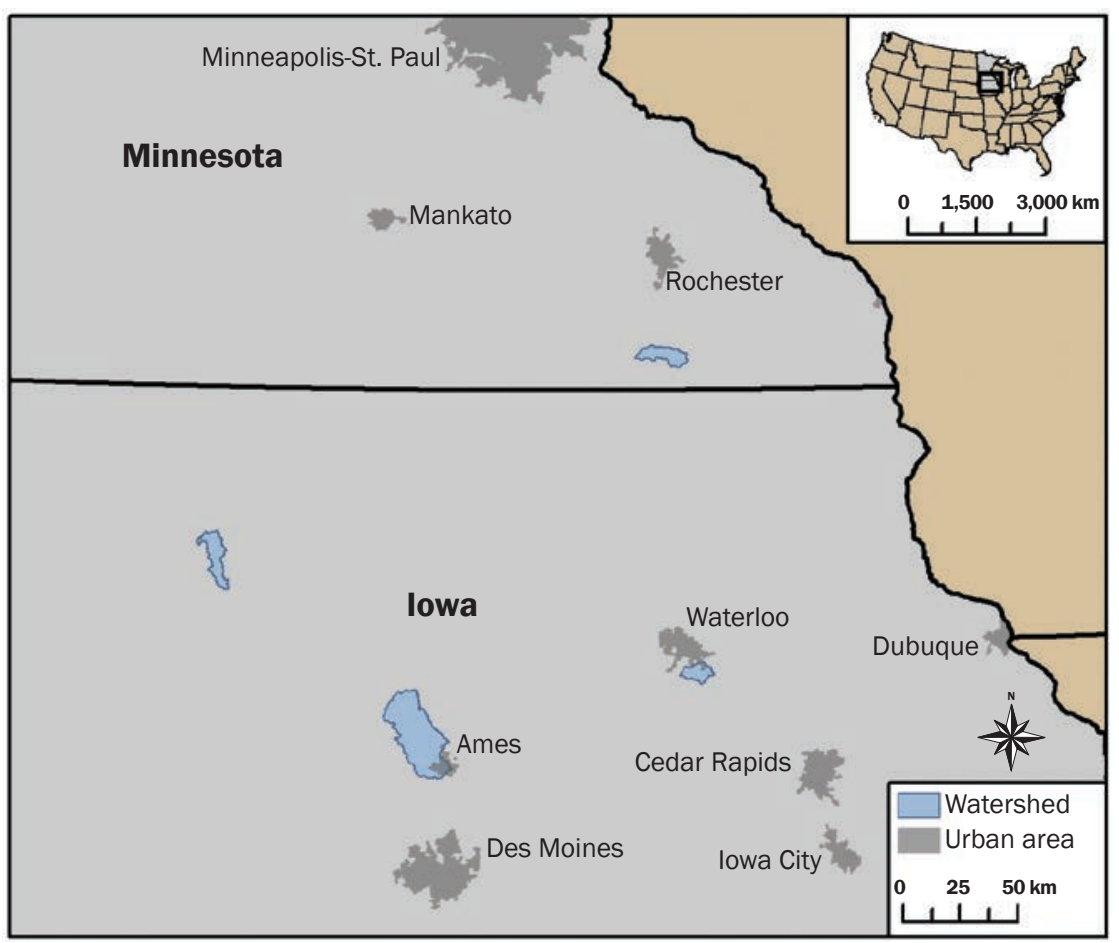

Semistructured interviews were conducted with 15 farmers across the four watersheds between November of 2016 and June of 2017. All interviews were conducted individually in person, except one in which two farmers were interviewed together. Interviewees were recruited based upon their interaction with the local conservation planner in their respective watersheds. In each watershed, the local conservation planner was asked to identify farmers with whom they had used ACPF results to discuss specific conservation opportunities on their farm. We were especially interested in learning about farmers' perceptions toward the process by which conservation opportunities were discussed with them, including their perception toward maps showing specific opportunities for conservation practices on their farm. The average age of farmers in our study was 58 years, and their formal education ranged from high school to graduate degree. Across the four watersheds, interviewees represented diversity with respect to farm size, age, formal education, and years of farming experience.

Interviews were conducted until we reached saturation, i.e., until the point when additional interviews were not revealing any new themes (Charmaz 2006). Indeed, from at least two or more watersheds, had to independently identify it.

\section{Results and Discussion}

We present evidence in support of farmers' perceptions toward conservation targeting and a discussion of farmers' receptiveness toward targeted conservation practice-placement options. We also explore factors influencing their receptiveness toward those placement options and whether or not the targeting process and the ACPF-generated maps motivate conservation behavior. In the last section, we make several recommendations for practitioners using a precision approach to conservation planning. We conclude with a synthesis of farmers' views and perceptions toward the process by which targeted practice-placement options were discussed with them, as well as their views and perceptions toward the ACPF-generated maps showing conservation practice options for their farms. We present these findings in relation to whether and how the targeting process and the maps affected farmers' willingness to adopt the ACPF-identified conservation practice(s).

Farmers'Views of Conservation Targeting. Disproportionate environmental impacts of the agricultural landscape provide a pragmatic rationale for conservation targeting. Scholarly evidence suggests that farmers support conservation targeting (Arbuckle 2013; Kalcic et al. 2014). All farmers in our study were also of the opinion that conservation practices should be implemented in locations where they provide maximum benefits at the least cost. Expressing their support for conservation targeting, a farmer mentioned:

I think we should be focusing our resources where we can have the greatest impact. So, rather than employing cover crops across the entire watershed, maybe we should take the same amount of investment and invest it in an easement on one property [resulting in] the greatest benefit with the least cost.

For most farmers, prioritizing conservation practices in locations where they do the most good for water quality at the least cost, made logical sense. For example, “... you get the most return from your investment [by focusing on areas of greatest conservation need]...I guess it would just make sense you 
should spend your money where it's really needed." Another farmer mentioned:

...to me, it just makes sense-let's fix the main arteries before we start worrying about the small bleeders...let's take care of the big problems... and if there are dollars left, we can pan out and take care of smaller ones. So, I guess, economically, I just think it's the biggest bang for your buck.

The phrase "biggest bang for the buck" was explicitly mentioned by several farmers in our study. Another farmer felt that while targeting made logical sense, it also had the potential to motivate farmers/landowners previously not interested in conservation. They mentioned:

I think that [targeting] kind of make sense, because then you are targeting real problem areas. But second, if you boost that incentive [for adoption of conservation practice on problem areas], you can get the more reluctant producer or the more reluctant landlord to look a little bit more at it.

To sum up, we found that farmers' support for conservation targeting was primarily based on the rationalization that limited resources should be spent where they bring the most good-a logical argument. However, does this logical support for targeting hold when the same farmers are the recipients of "targeted" practices? With this evidence highlighting that farmers support conservation targeting, we now turn our attention to understanding farmers' perceptions of targeting when their farm is identified as a CSA, i.e., when practice options are identified specifically for their farm.

Farmers as Recipients of Precision Conservation Planning Results. Farmers in this study were recipients of ACPFgenerated conservation planning options, i.e., conservation planners in their respective watersheds recommended farmers to adopt conservation practice(s) on their farm based on the results generated by the ACPF. Maps showing conservation opportunities, both in-field and across the watershed, acted as the primary medium by which conservation planners engaged farmers in respective watersheds. Results from the ACPF toolbox were shared with farmers in diverse contexts. For example, in the southeastern Minnesota watershed (figure 2), conservation planners predominantly shared ACPF results oneon-one with farmers, in the form of an individualized, easy to understand report of conservation practices suggested for their farm. In two out of the three Iowa watersheds, the overarching focus was on engaging farmers and other watershed stakeholders in the watershed planning process. As part of this process, ACPF results were shared with farmers at local and regional meetings, organized either as a conference or an open house. This was followed by one-on-one interaction with interested farmers. In the third Iowa watershed, ACPF results were shared with farmer members of the local watershed advisory council.

Factors Influencing Farmers' Receptiveness toward Precision Conservation Results. Interviews revealed several factors influencing farmers' receptiveness toward targeted practice-placement options. In this section, we present a synthesis of these factors, such as farmers having autonomy in the targeting process, and perceiving that the targeting process had several benefits.

Process Autonomy: Ownership, Flexibility, and Voluntary Nature. Farmers in our study often expressed the importance of having autonomy in the targeting process, including having a sense of ownership and flexibility. Expressing the theme of ownership in the targeting process, a farmer mentioned:

... [the process] made it feel like it was our decision to do it [adopt a suggested conservation practice] rather than somebody telling you to do it...I guess that's probably the value of what I [have] seen that's different [in this watershed project] than what has been historical. There's things that [we have] been involved in.

Interviewees also felt it was important that the targeting process was flexible and that it was perceived by farmers to be voluntary. For example:

...we asked them [conservation planners] to make them [the waterway] actually four feet wider, which took up more acres but it reduced the pitch or the slopes coming in and out of them so it was easier on equipment of things going in and out of them. So, there was some flexibility there in that process.
Further emphasizing the importance of having flexibility in the targeting process, a farmer mentioned:

I think it's important that we allow producers flexibility within finding solutions because there isn't a one-size-fits-all answer. So that's what I like about how this [ACPF map] has been administered so far in our watershed because we've been bringing people along on a journey and allowing people to participate at the level that they're comfortable.

Benefits Associated with Conservation Targeting: Field-Scale Validation of Natural Resource Concerns. Several farmers felt that the process of conservation planners sharing maps showing conservation opportunities helped validate their own experiential knowledge about the areas of concern on their farm. Expressing this theme, a farmer mentioned:

When you walk past a problem every day, you don't see it after a few trips by it. You become blind to it. And I knew [the conservation planner] was on farm to find those things. And it is hard to hear that you have things you can improve, it just is... [The process of sharing ACPF results] made me aware of those things I had just stopped seeing anymore.

A convergence between the field-scale experiential knowledge of the farmer and conservation planner's technological knowledge and expertise-based off the ACPF toolbox-subsequently enhanced farmers' comfort level of working with them. For example, a farmer mentioned:

...whenever the party that is delivering the map brings me a map of a farm that I've been farming on for 30 years, they're not going to bring me a lot of surprises... by the time they get done presenting the map you know what they know, what you know. So you say, "All right. They're saying the same thing that I see every day when I work that field or what I do," so it gives you a higher comfort level with the party that you're dealing with.

For others, maps enabled identification of specific areas on their farm where con- 
servation practices could be implemented. They mentioned:

Well, of course, I couldn't identify spots [where conservation practice could be implemented], but [the conservation planner] was able to identify areas along the drainage ditch that might possibly be available for the [conservation] practice I was considering...So, maybe it [using maps] makes the process [of promoting conservation practices] go faster...

\section{Benefits Associated with Conservation Targeting: Encourages Watershed Thinking. Farmers often reflected upon the process by which conservation opportunities were dis- cussed with them, in particular the role of maps showing conservation practice-place- legend] and you say, "Okay, I can do a multi-species buffer, [that] is what would work in that area." So, it gives you a tool to say, "Okay, well that would be a good starting point to start a conversation [with a conservation planner]."} ment options, in encouraging watershed thinking. Maps encouraged watershed thinking among farmers by elevating awareness of the flow of water on their farm and how that relates to water flows in the watershed, and by promoting awareness of water quality. Expressing the theme of maps encouraging watershed thinking, a farmer mentioned:

...there was a lot of information shared [as part of the process of sharing ACPF results]...[water] exits out the side of our bluffs, into our creeks and streams...you learn some of that... along the way, I guess, [and that's]... when you start talking about water quality long term.

Another farmer mentioned:

It [the ACPF watershed scale map] shows you the big picture, and sometimes the farmer doesn't think about that... Yeah, the water runs that way, but they don't catch if the water runs into this little creek that runs into this bigger creek that runs into the river, and it goes right in the town of Ames.

For farmers who are already thinking at the watershed scale, the maps proved to be a medium for cognitive reinforcement. For example, a farmer mentioned, "Well, it's something we're already thinking of [thinking at watershed scale], but this does confirm you need to think that way." For others, maps were perceived as a medium that not only encouraged watershed thinking, but also facilitated communication between the farmer and the conservation planner, and subsequently had the potential to motivate conservation behavior. For example, a farmer mentioned:

I think that it does help [encourage watershed thinking]...for example...if I'm living in that pink [field with a suggested conservation practice] and I'm thinking, "Well, I'm a long way from that water source, there." I'm looking at the pink thinking, "Well, what can I do?" Well, then you go over there [to the map

\section{Benefits Associated with Conservation} Targeting: Maps as a Visualization and Communication Tool. Maps were perceived as an effective visualization and communication tool by farmers. For example, a farmer mentioned, "I think it's [the ACPF map] a good tool to get the conversation started." Emphasizing the visualization potential of maps, a farmer mentioned:

The one [map] that I thought was very useful...showed a couple of farms that we have where the computer recommended there be a waterway installed or lengthened, where it could see actually where the residue had moved. On most of our farms we know where them areas are already, but when you visualize it, it makes it look a little different, and that's very helpful to me. I think most farmers would agree with that... If you can visually see, and especially touch something as a farmer, that means a lot more.

Whereas some farmers perceived maps as a beneficial visualization and communication tool for themselves, others felt that the communication potential of maps would also be a benefit for conservation planners. Farmers felt that the maps equipped conservation planners with a medium to have a more meaningful and directed conversation with them about conservation practices suitable for their farm. Explicitly highlighting the potential of maps for conservation planners working in the USDA Natural Resources Conservation Service (NRCS), a farmer mentioned:
I think this [ACPF generated map] is...a tool for the NRCS to use...[it] helps a little bit with the sale [promoting conservation practices] too... They can show me one of these maps...open it up to the page that's appropriate to the client [farmer] that you're talking to and show what their potential. It's something that's very useful for the NRCS....

Another farmer mentioned, "I guess it's easier for somebody from the NRCS to have a map and show you spots that a practice can be initiated, as opposed to just walking out and saying, "Well, maybe we can do one here or something."' Farmers also felt that the maps would be an important communication tool for conservation planners working in the capacity of watershed coordinators. For example, a farmer mentioned, "I know my problems, and I try to take care of them without a fancy map...The people [watershed coordinators] that's got to talk to all these farmers out here [in the watershed], I can see where it'd be a great tool for them...."

Implications of Targeted Conservation Planning Results for Conservation Behavior. Perhaps the most salient benefit of conservation targeting is if it motivates farmers to adopt conservation practices. Subsequently, we were interested in understanding whether using maps as a medium of sharing targeted practices motivated farmers to engage in conservation behavior. To that end, we asked farmers in this study whether the map(s) showing conservation opportunities motivated them to adopt conservation practices. In response, a farmer mentioned:

I would say yes just from the aspect [that] you can visually see the trouble spots. Instead of just being on the farm and going out looking at them, you could actually have a piece of paper, set it on your desk and look at it this week, come back to it again and go, "Hey, I probably really ought to do something in that area..." So, that's where...the maps helped the most.

Whereas the aforementioned quote bolsters the role of maps in providing field-scale issue validation for farmers, a benefit of maps we identified earlier, it also suggests their potential in subsequently motivating conservation behavior. Maps also acted as a medium to educate farmers about new conservation practices and discuss conserva- 
tion opportunities for their farm, and more broadly, serve as a communication tool. By acting as an educational and communication tool, maps subsequently motivated farmers to engage in conservation behavior. Highlighting several of the aforementioned themes, a farmer mentioned:

I never really thought too much about bioreactors or saturated buffers just because I don't know that much about them, they're much less common. So, without seeing maps like this, I probably wouldn't have looked into it very much.

The interviewee further added:

I think it's nice to see your specific land and recommendations tailored directly to that land, versus when you just go to a meeting that says, 'cover crops are good. Doesn't matter where your land is, cover crops are good.' Well that's all fine... but if you can see it with your field specifically marked, I think it helps.

Highlighting the communication potential of maps, a farmer mentioned:

...you could use a map to pique the farmer's interest...it's nice if somebody comes out with a map and shows you where you could do some of these things [conservation practices], as opposed to saying, "Well, we'd like to have you consider practices on your farm" ...I think a map would pique their interest more.

A farmer recognized the potential of maps in motivating conservation behavior but emphasized the importance of using maps as a medium to communicate not only the location of conservation practice(s), but also why the practice would be beneficial in that particular location. The farmer mentioned:

The map shows that they'd [conservation planner] like to do this [conservation practice] in that location. And to that point, yes, it motivates me [to adopt conservation practices]. But if you could tell me, "Well, we've got good reason to believe that we can get some advantage if we put in a bioreactor here," ...the map does help show where you want to do that [implement a practice], but it doesn't say beyond that. [The map] is a tool to help show what you want to do. And in that end of it, yes, it helps me realize what you're talking about. It helps us communicate.

We also asked farmers whether maps helped inform their approach to conservation decision-making. In response, a farmer mentioned, "[For saturated buffer], yes. It's due to the map...We thought about doing something like this. But we just didn't know how it would work or where it would work, and the maps allowed that to be seen." Overall we found that farmers were receptive toward using maps as a medium to discuss targeted conservation practice-placement options, which in turn motivated them to engage in conservation behavior.

Recommendations for Conservation Targeting. Farmers often drew upon their experience of working with conservation planners in respective watersheds, and made several recommendations to conservation planners for use of targeted conservation planning results. We present those practitioner-oriented recommendations in this section.

Recommendations for Improving Conservation Planning Maps. Maps showing conservation opportunities were the primary medium by which targeted recommendations were shared with farmers. Subsequently, farmers made recommendations for improving the maps. Several farmers showed interest in making the maps digital and interactive. For example, a farmer mentioned, "If there was a way to see them [the maps] in 3D, that would be what I would like to see... if there was a way to take that troubled area [area with resource concerns] and be able to see the topography more, that would be interesting." Another farmer mentioned, "You could make it [the map] digital so then people could zoom in as close as they wanted to." Making the maps interactive and scalable enabled farmers to view information across scales, while also allowing them to screen out information that they felt was not relevant for their operation. For example, a farmer mentioned, "I would prefer to look at it [the map] on an interactive basis so that I could screen out and make it less busy. So, let's look at this practice only and then interact with that." On a similar note, farmers had recommendations for both the scale of the map and the amount of information presented to them. Some farmers felt that conservation planners should avoid presenting too much information on the map, therefore avoiding a situation when farmers feel that the map has "a lot going on." Highlighting this aspect, a farmer mentioned:

The maps were very accurate but sometimes it is almost too much...even if you put a waterway on every one of those spots [identified on the map] it gets to the point where it makes it really hard to farm it. So, you've got to have a happy medium, at least some kind of balance there.

Scale at which information was shared emerged as another important consideration. Highlighting the value in sharing both field- and watershed-scale information, a farmer mentioned:

...you need to know where you're at in the big picture, what's above you, what are the neighbors doing, things like that. But when it comes to the practice that you're intending to implement or discussing, you need it very localized...So yeah, you frequently need both. You need the very localized, exact point, and then you need the bigger scale.

While the scale of the map and its information content emerged as important considerations, a farmer drew conservation planner's attention to the nuance of information presented on the map. The farmer mentioned:

As students we never liked red ink, and we pointed out to [the conservation planner], maybe he shouldn't use red ink on the maps. It's just one of those things that, yes, these areas need work. There are things we can do. It's the low hanging fruit but, I don't like red ink.

Recommendations for Improving the Process of Sharing Targeted Conservation Planning Results. In addition to making specific recommendations for the maps, farmers made several recommendations for the process by which conservation practice-placement options were discussed with them. Whereas having process autonomy emerged as a theme influencing farmers' receptiveness toward conservation targeting, this also emerged as a recommendation. Allowing farmers some flexibility in the decision-making process, and presenting planning options as suggestions as opposed 
to prescriptions or recommendations, emerged as two important considerations for improving the process of sharing targeted conservation planning results. For example, a farmer mentioned:

The main thing is just tell them [farmers] we're just showing [conservation opportunities] as a recommendation. It is not a hear-all, end-all, that if we bring this to you, you have to do this. It's just showing you where something can be implemented.

Another farmer expressed the theme of making the process flexible, while also emphasizing the importance of using local faces and building relationships. They mentioned:

...you're going to encounter varying degrees among farmers of receptivity on using something like this [maps showing conservation opportunities]...with the more skeptical producers, it's probably best to have somebody who's familiar with the area, familiar with the producer, familiar with the parcels... at the very least, remove certain layers, like, "We are going in to meet with [a farmer], and there's no way we're going to talk him into contour buffer strips. So, let's just take that one off." Or, "Here's what we started with. If you're interested in contour buffer strips, we could talk about that. But assuming you're not, let's talk about these other things." It's a relationship business... You can't get away from that, so that really is important.

Another important recommendation for the targeting process pertained to the context in which practice-placement options were presented. Specifically, this recommendation pertained to whether information was shared individually or in a group setting. Farmers often felt that whereas meeting in a small group setting was beneficial for sharing information, motivating them to act on the information required one-on-one interaction. For example, a farmer mentioned:

I would say a group to start with. And then when you get that [farmer] a little taste of it...and they feel comfortable... that's when you bring in the one-onone conversation, and you can set up a one-on-one meeting. And that's what we found works best...a meeting format is good for the information, but sometimes to actually get people interested, it has to be a one-on-one.

\section{Another farmer mentioned:}

It [the process] would be [to] basically start at the small groups, and the NRCS usually holds one, or two, or three meetings a year in the county. And have it start there with those [farmers] and then go to the oneon-one meetings.

Whereas this quote highlights the importance of transitioning from a group to an individual setting, it also highlights the importance of the messenger, i.e., the person or the entity that is sharing targeted conservation planning results. Crop advisors and the NRCS emerged as potential messengers for sharing targeted practice options. For example, a farmer mentioned:

Probably my feeling would be that I'd like to work with my crop advisor. Because at this point, we know the overall problems. Now we have to implement [suggested conservation practices] into the farm to be able to make it worth dollars and cents. They need to know what I want to do.

Another farmer mentioned, "Well, I think maybe the NRCS is probably the place to do that [share practice-placement options], and maybe a crop advisor could advise you on it, too." A more nuanced consideration in relation with the messenger was their personality. For example, a farmer mentioned, "He [conservation planner] just seemed like a very down-to-earth type person. Wasn't pushy. Was willing to work with whatever you wanted to try to do to help improve your farm."

Having Boots on the Ground. Although DSTs such as the ACPF equipped conservation planners with maps and data sets that enabled farmer engagement, farmers felt it was important for conservation planners to have boots on the ground. For example, a farmer mentioned:

I think the maps are a great starting point, but then you have to go to the field and walk it and say, "The map showed me this area and this area. Let's look at those areas and then make a decision." Rather than just trying to make...a decision only off the map.
Another farmer mentioned, "I think it [the map] wasn't really very hard to understand... But you got to go from the map, then you got to go out and do the leg work on it." Having boots on the ground served a dual purpose. Firstly, it helped validate the ACPFgenerated results, thereby accounting for how the farm is managed. Secondly, it provided an avenue for farmer engagement, thereby providing an opportunity to build relationships. For example, a farmer mentioned, "I think that the relationship comes first. So, I think you have to have boots on the ground in watersheds to have success."

\section{Summary and Conclusions}

Scholarship on human dimensions of conservation targeting is growing. Much of our understanding is based off scholarship that either examines farmers' generalized perceptions toward conservation targeting (Arbuckle 2013), or actively engages farmers in generating targeted recommendations (Kalcic et al. 2014, 2015; Zimmerman et al. 2019). We help advance the scholarship on human dimensions of conservation targeting by focusing on farmers whose fields were identified in a set of watershed-scale precision conservation options generated by the ACPF, a toolbox that provides a menu-driven approach to conservation prioritization and targeting.

We found that farmers in our study had positive views of conservation targeting, often based on cost-benefit rationalization that limited public and private resources should be spent where they bring the most good, supporting the current understanding of farmers' positive attitudes toward conservation targeting (Arbuckle 2013; Kalcic et al. 2014). However, we also found that farmers' generalized support for conservation targeting translated into being receptive toward practice-placement options made specifically for their farm. This finding is in contrast with scholars who found that while farmers were generally receptive toward conservation targeting, they expressed concerns about the application of those planning options made for their own land (Zimmerman et al. 2019). In the Zimmerman et al. (2019) study, loss of autonomy was one of several concerns expressed by farmers. Indeed, as we found, having autonomy in the targeting process had a positive influence on farmers' receptiveness toward targeted conservation.

An aspect of process autonomy farmers valued was the perception that practice-placement 
options were flexible - a finding also supported by current scholarship (Ahnström et al. 2009; Kalcic et al. 2014, 2015). However, using static maps as a medium of sharing information presents a challenge because they may give the impression that the information presented is inflexible. Indeed, there is a fine balance between presenting information as flexible, therefore open for refinement and discussion, versus presenting information as inflexible. While presenting information as flexible provides an avenue to bolster farmers' sense of autonomy in the process, conservation planners should be mindful that flexibility is not perceived incorrectly by farmers as uncertainty, which could then be used as a means to discredit the science (Gallo and Goodchild 2012). Since our interviews, ACPF story maps have been developed in a readily accessible format via ArcGIS online (Esri 2019), where it is possible to provide access to ACPF results, rescale maps, and show selected practices or combinations of practices.

A core question we sought to answer in this study was whether farmers' generalized support for conservation targeting translated into support for precise practice-placements for their own farm, and subsequently motivated them to engage in conservation behavior. Farmers in this study were supportive of the concept of conservation targeting, as well receptive toward options identified for their farm. They were also motivated to adopt practices identified for their farm.Vulnerability of farmland to erosion and sedimentation problems has been identified as a motivation for farmers to adopt conservation practices (Prokopy et al. 2019; Ranjan et al. 2019a). Our study confirms this, but also indicates the potential of conservation targeting process and the maps used to share practice-placement options in motivating conservation behavior. To achieve this potential, conservation planners could design education and outreach activities that help promote benefits associated with conservation targeting. While promoting these benefits can be a salient starting point, it is important to also keep in mind that the targeting process should impart a sense of ownership, i.e., has a space for bottom-up feedback, and is flexible to accommodate suggestions. The process should also come across as suggestive, not prescriptive, for farmers. In this regard, conservation planners can draw upon insights from stakeholder engagement approaches when using GIS data (Craig and Elwood 1998; Sieber 2006).

Farmer engagement under the purview of conservation targeting is a function of both the process by which targeted practice-placement options are discussed with farmers, as well as the medium by which these options are presented. To that end, we made several practitioner-oriented recommendations for both the targeting process and the maps used to share targeted practice-placement options with farmers. Interviews revealed the importance of one-on-one interactions with farmers, emphasizing the importance of having agricultural conservation policy fund the human side of conservation (Osmond et al. 2015; Ranjan et al. 2019b).

We acknowledge a limitation to this research from only interviewing farmers who had worked with conservation planners in respective watersheds. Doing so was important given our goal of understanding farmers' perceptions of ACPF-generated results for their farm. Future research should work on generalizing the results of this study through a representative survey design. By employing an exploratory, qualitative approach, we were able to identify factors that potentially mediate farmers' support for conservation targeting. The onus is on future scholarship to test their effects, and relative significance, in predicting farmers' support for conservation targeting. Whereas our focus was on generating a holistic understanding of farmers' receptiveness toward targeted conservation, future scholarship should consider teasing apart the effects of the targeting process, and the medium, i.e., the maps, in influencing conservation behavior. Indeed, going forward, we suggest that scholars should not only assess farmers' generalized attitudes toward targeting, but also be mindful of the nuances of the "farmer engagement" process, and the medium, i.e., the maps used for engaging farmers. A congruence between farmers' general attitudes toward targeting combined with their receptiveness toward the targeting process and the medium, we argue, has the potential to move the needle toward implementing conservation practices at sites where they provide the maximum environmental benefit. A final point of emphasis is the recognition that a DST is only as good as how the local conservation planners use it, consistent with implementation of other programs and tools to increase adoption of conserva- tion practices (Church and Prokopy 2017). Therefore, we cannot emphasize enough the role of local conservation agency staff in providing the impetus for the success of conservation targeting.

\section{Disclaimer}

Mention of trade names or commercial products in this publication is solely for the purpose of providing specific information and does not imply recommendation or endorsement by the US Department of Agriculture (USDA).

\section{Acknowledgements}

The authors would like to thank the farmers who agreed to be interviewed for this research. The authors would also like to thank David James (geographic information specialist at the National Laboratory for Agriculture and the Environment, USDA Agricultural Research Service, Ames, Iowa) and Jackie Getson (research associate and outreach coordinator in the Department of Forestry and Natural Resources at Purdue University, West Lafayette, Indiana) for the ACPF-generated map and a map of the study watersheds, respectively. This research was funded by the US Environmental Protection Agency, Federal grant \#83675501, and supported by a USDA interagency agreement between the Agricultural Research Service and the Natural Resources Conservation Service. USDA is an equal opportunity provider and employer.

\section{References}

Ahnström, J., J. Höckert, H.L. Bergeå, C.A. Francis, P. Skelton, and L. Hallgren. 2009. Farmers and nature conservation: What is known about attitudes, context factors and actions affecting conservation? Renewable Agriculture and Food Systems 24(1):38-47, https://doi. org/10.1017/S1742170508002391.

Arbuckle, J.G. 2013. Farmer attitudes toward proactive targeting of agricultural conservation programs. Society \& Natural Resources 26(6):625-41, https://doi.org/10. 1080/08941920.2012.671450.

Charmaz, K. 2006. Constructing Grounded Theory: A Practical Guide through Qualitative Analysis. London: Sage Publications.

Church, S.P., M. Dunn, and L.S. Prokopy. 2019. Benefits to qualitative data quality with multiple coders: Two case studies in multi-coder data analysis. Journal of Rural Social Sciences 34(1).

Church, S.P., and L.S. Prokopy. 2017. The influence of social criteria in mobilizing watershed conservation efforts: A case study of a successful watershed in the Midwestern US. Land Use Policy 61:353-367.

Craig, W.J., and S.A. Elwood. 1998. How and why community groups use maps and geographic information. Cartography and Geographic Information Science 25(2):95-104, https://doi. org/10.1559/152304098782594616. 
Duriancik, L.F., D. Bucks, J.P. Dobrowolski, T. Drewes, S.D. Eckles, L. Jolley, R.L. Kellogg, D. Lund, J.R. Makuch, M.P. O'Neill, C.A. Rewa, M.R. Walbridge, R. Parry, and M.A. Weltz. 2008. The first five years of the Conservation Effects Assessment Project. Journal of Soil and Water Conservation 63(6):185A-197A, https://doi. org/10.2489/jswc.63.6.185A.

Esri. 2019. ArcGIS online. Redlands CA: Esri. https://www. arcgis.com/.

Gallo, J., and M. Goodchild. 2012. Mapping uncertainty in conservation assessment as a means toward improved conservation planning and implementation. Society \& Natural Resources 25(1):22-36, https://doi.org/10.108 0/08941920.2011.578119.

Guest, G., A. Bunce, and L. Johnson. 2006. How many interviews are enough?: An experiment with data saturation and variability. Field Methods 18(1):59-82, https://doi.org/10.1177/1525822X05279903.

Kalcic, M.M., J. Frankenberger, I. Chaubey, L.S. Prokopy, and L. Bowling. 2015. Adaptive targeting: Engaging farmers to improve targeting and adoption of agricultural conservation practices. Journal of the American Water Resources Association 51(4):973-91, https://doi. org/10.1111/1752-1688.12336.

Kalcic, M., L. Prokopy, J. Frankenberger, and I. Chaubey. 2014. An in-depth examination of farmers' perceptions of targeting conservation practices. Environmental Management 54(4):795-813, https://doi.org/10.1007/ s00267-014-0342-7.

Konopacky, J., and L. Ristino. 2017. The healthy watershed framework: Revising Clean Water Act and Farm Bill conservation programming to catalyze small-scale watershed planning and implementation. Environmental Law Review 47(3):647-93. http://elawreview.org/ articles/healthy-watershed-framework-blueprintrestoring-nutrient-impaired-waterbodies-integratedclean-water-act-farm-bill-conservation-planningimplementation-subwatershed-1/.

Nowak, P., S. Bowen, and P.E. Cabot. 2006. Disproportionality as a framework for linking social and biophysical systems. Society and Natural Resources 19(2):153-73, https:// doi.org/10.1080/08941920500394816.

Osmond, D.L., D.L. Hoag, A.E. Luloff, D.W. Meals, and K. Neas. 2015. Farmers' use of nutrient management: Lessons from watershed case studies. Journal of Environmental Quality 44(2):382-390.

Porter, S.A., M.D.Tomer, D.E.James, and J.D.Van Horn. 2018. Agricultural Conservation Planning Framework ArcGIS Toolbox User's Manual, Version 3. Ames, IA: National Laboratory for Agriclture and the Environment, USDA Agricultural Research Service.

Prokopy, L.S. 2011. Agricultural human dimensions research: The role of qualitative research methods. Journal of Soil and Water Conservation 66(1):9A-12A, https://doi. org/10.2489/jswc.66.1.9A.

Prokopy, L.S., K. Floress, J.G. Arbuckle, B. Gramig, S.P. Church, F.R. Eanes, Y. Gao, P. Ranjan, and A.S. Singh.
2019. Adoption of agricultural conservation practices in the United States: Evidence from 35 years of quantitative literature. Journal of Soil and Water Conservation 74(5):520-34, https://doi.org/10.2489/jswc.74.5.520.

Ranjan, P., S.P. Church, K. Floress, and L.S. Prokopy. 2019a. Synthesizing conservation motivations and barriers: What have we learned from qualitative studies of farmers' behaviors in the United States? Society \& Natural Resources 32(11):1171-1199, https://doi.org/ 10.1080/08941920.2019.1648710.

Ranjan, P., A.S. Singh, M.D. Tomer, A.M. Lewandowski, and L.S. Prokopy. 2019b. Lessons learned from using a decision-support tool for precision placement of conservation practices in six agricultural watersheds in the US Midwest. Journal of Environmental Management 239(June):57-65, https://doi.org/10.1016/j.jenvman. 2019.03.031.

Rose, D.C., W.J. Sutherland, C. Parker, M. Lobley, M. Winter, C. Morris, S. Twining, C. Ffoulkes, T. Amano, and L.V. Dicks. 2016. Decision support tools for agriculture: Towards effective design and delivery. Agricultural Systems 149:165-74, https://doi.org/10.1016/j. agsy.2016.09.009.

Sieber, R. 2006. Public participation geographic information systems:A literature review and framework. Annals of the Association of American Geographers 96(3):491-507, https://doi.org/10.1111/j.1467-8306.2006.00702.x.

Tomer, M.D., S.A. Porter, K.M.B. Boomer, D.E. James, J.A. Kostel, M.J. Helmers, T.M. Isenhart, and E. McLellan. 2015. Agricultural Conservation Planning Framework: 1. Developing multipractice watershed planning scenarios and assessing nutrient reduction potential. Journal of Environment Quality 44(3):754, https://doi. org/10.2134/jeq2014.09.0386.

Tomer, M.D., S.A. Porter, D.E. James, K.M.B. Boomer, J.A. Kostel, and E. McLellan. 2013. Combining precision conservation technologies into a flexible framework to facilitate agricultural watershed planning. Journal of Soil and Water Conservation 68(5):113A-120A, https://doi. org/10.2489/jswc.68.5.113A.

Viera, A.J, and J.M. Garrett. 2005. Understanding Interobserver Agreement: The Kappa Statistic. Family Medicine 37(5):360-63.

Zimmerman, E.K., J.C. Tyndall, L.A. Schulte, and G.L.D. Larson. 2019. Farmer and farmland owner views on spatial targeting for soil conservation and water quality. Water Resources Research 2018WR023230, https:// doi.org/10.1029/2018WR023230. 